\title{
RELAÇÕES DE GÊNERO NA POLÍCIA MILITAR: NARRATIVAS DE MULHERES POLICIAIS
}

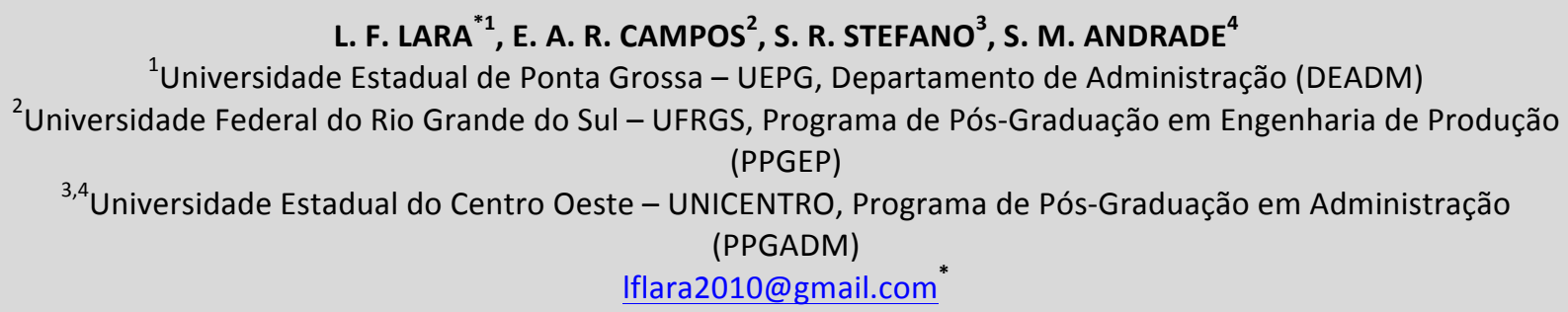

Submetido em 06/02/2016 - Aceito em 21/06/2017

DOI: $10.15628 /$ holos.2017.4078

\section{RESUMO}

Em um regime totalmente masculinizado e simbolizado pela força de trabalho do homem, a presença feminina nos batalhões consegue evidenciar um princípio de militarismo, onde prevalece não apenas a força física característica e atribuído aos homens, mas sim atributos individuais como: coragem, dedicação e isso se traduzem em competências e habilidades que podem ser encontrados também na mulher. $O$ objetivo deste estudo foi analisar as relações de gênero no contexto de trabalho das policiais militares de um Batalhão da Polícia Militar (BPM). Foi utilizada a metodologia de estudo de caso qualitativo, sendo que foi realizado entrevistas, com roteiro semiestruturado, com oito mulheres policiais e o responsável pelo comando do batalhão. Foi possível concluir que, o trabalho militar antes estereotipado como lugar de homens, vem tendo mudanças consideráveis, desde a década de 1990. Foi possível observar ainda que em um universo de 19,5 mil policiais em todo o Paraná, o número de mulheres ainda é baixo, no entanto pode ser percebido com base nas entrevistas das mulheres que há muito empenho e dedicação, e que o ingresso dessas se deu tardiamente na profissão de policial militar.

PALAVRAS-CHAVE: Gênero, Relações, Policia Militar.

\section{GENDER RELATIONS IN MILITARY POLICE: POLICE WOMEN'S NARRATIVE}

\begin{abstract}
In a fully masculinized and symbolized by the force of the man's work arrangements, women's presence in battalions can demonstrate a principle of militarism, which prevails not only physical strength and tribute characteristic attributed only to men, but individual attributes such as: courage, dedication and that translate into skills and abilities that can also be found in women. The objective of this study was to analyze gender relations in the workplace of a military police Military Police Battalion (MPB). The methodology of qualitative case study, and was conducted interviews
\end{abstract}

with semi-structured, with eight police and women responsible for battalion command was used. It was concluded that the military work before stereotyped as a place for men, has had considerable changes since the 1990s. It was also possible to observe that in a universe of 19,500 police officers across the Paraná, the number of women is still low, however it can be perceived based on interviews of women who long commitment and dedication, which is the entry of these given later in the profession of police officer.

KEYWORDS: Gender, Relations, Military Police. 


\section{INTRODUÇÃO}

A luta travada pelas mulheres para que conseguissem espaço e reconhecimento na sociedade, pelo menos na ocidental, foi longa e árdua. A conquista de direitos iguais aos dos homens, como o de votar e o de emprego, por exemplo, foi realizada mediante décadas de reivindicações e lutas políticas. Nesse contexto o movimento feminista teve um papel fundamental, a partir de seu surgimento, na França, em 1789 (Gurgel, 2010).

As teorias feministas liberal, radical, psicanalítica, marxista, socialista, pósestruturalista/pós-moderna, terceiro-mundista/pós-colonialista têm influenciado os estudos organizacionais no tocante às relações e contrastes entre gêneros (Calás \& Smircich, 2007). O fato que muitos estudos feministas têm apontado para as iniquidades e desigualdades cometidas nas organizações, contra as mulheres, principalmente a participação no poder organizacional e de planejamento do seu próprio destino no interior dessas organizações (Acker, 2006).

A respeito dos avanços sentidos em relação ao gênero masculino no âmbito social, mesmo na atualidade, os desafios muitas vezes superados pelas mulheres são muito maiores que do sexo oposto. Conforme Del Priore \& Bassanezi (2007) em um contexto amplamente considerado de extremo preconceito, a incorporação das mulheres no mercado de trabalho, ou seja, fora do lar, em uma sociedade marcada por um crescimento vertiginoso, passou a ser vista e discutida, juntamente, com temas que desvalorizavam sua imagem perante a sociedade, como adultério, virgindade, casamento e prostituição. A partir desse nivelamento de temas, estão presentes os indícios de discriminação pela qual foram submetidas às mulheres ao longo dos anos, aquelas com dupla jornada de trabalho - no emprego e no lar - principalmente até a década de 2000.

Porém poucos são os estudos que discutem as relações de gênero, dentre estes podem ser citados os estudos de Camargos et al.,(2014) Fernandes et al., (2008) avaliando o enfrentamento das mulheres entre 15-24 anos no mercado de trabalho; Barbosa (2013) buscando compreender o trabalho das mulheres no mercado e aspectos voltados à competência. Porém nota-se a limitação de estudos que expõem a temática das mulheres na carreira militar. Cappelle \& Melo (2010), buscaram compreender as características da mulher que escolhe ser policial, o seu papel no dia-adia na tentativa de melhorar as interações sociais em uma sociedade a partir do combate intenso da criminalidade. As autoras concluem que o trabalho das policiais está marcado pelas relações de poder e de gênero assim como as dificuldades que encontram no exercício de sua função.

A busca por compreender as relações existentes no trabalho estereotipado de uma sociedade "conservadora" que ainda está se adequando a compreender o papel da mulher em cargos antes ocupados apenas por homens, suscitou a questão que motivou o presente estudo. Como se desenvolvem as relações de trabalho entre homens e mulheres no contexto de trabalho na Política Militar do Estado do Paraná?

Assim, tem-se como objetivo, analisar as relações de gênero no contexto de trabalho das policiais militares de um Batalhão da Polícia Militar do Interior do Estado do Paraná (BPM-PR). 
De forma a fim de melhor elucidar a exposição da temática, o presente estudo está dividido em três partes. Na primeira parte é apresentada uma discussão teórica a respeito da presença da mulher na sociedade e a sua inserção no mercado de trabalho. Na segunda parte são indicados os procedimentos metodológicos utilizados. Na terceira parte é apresentado a análise de resultados e por fim são elencadas as considerações finais do estudo.

\section{QUADRO TEÓRICO}

\subsection{A inserção Social da mulher no mercado de trabalho}

Ao longo da história, as mulheres após muitas lutas conseguiram transpor as barreiras do papel de ser apenas esposa, submissas a um regime em que o lugar da mulher era na casa cuidando dos afazeres domésticos. E a partir da década de 1970, essas mulheres "presas" ou "escravas" de um sistema totalmente regido pelos homens, foram conquistando um espaço maior no mercado de trabalho. O mundo, as tendências e o próprio crescimento das cidades foram cenários para que elas pudessem demonstrar seus valores femininos, e sua capacidade de trabalho em equipe estando inseridas ou não no mercado de trabalho. Na busca por vencer contra o antigo individualismo, a persuasão em oposição ao autoritarismo, a cooperação ao invés de competição, as mulheres hoje ocupam postos na estrutura de empregos que antes eram ocupados apenas por homens. E é por meio da capacidade delas que cada vez mais têm representatividade pelo seu trabalho, quer seja nas frentes políticas, ou nas ruas na tentativa de manter a ordem (Probst \& Ramos, 2003).

Entender que hoje ainda existam estigmas criados quanto à capacidade de uma mulher em desempenhar funções de liderança ou de poder, têm maior receptividade, porém em um período histórico não muito distante isso fugia dos princípios praticados por uma sociedade machista é o que relata Del Priore \& Bassanezi (2007, p. 579):

Lidamos muito mais com a construção masculina da identidade da mulher, do que com sua própria percepção de sua condição social, sexual e individual. Não é a toa que até recentemente, falar das trabalhadoras urbanas no Brasil significava retratar um mundo de opressão e exploração demasiada, em que elas pareciam como figuras vitimizadas e sem nenhuma possibilidade de resistência. Sem rosto, sem corpo, a operária foi transformada numa figura passiva, sem expressão política nem contorno pessoal.

No período de 2003 a 2010 foi lançado um documento pela Organização Mundial das Nações Unidas (ONU) em conjunto com a OngCepia, organização feminista de referência do Rio de Janeiro, intitulado "O Progresso das Mulheres no Brasil" que busca demonstrar a situação em que as mulheres brasileiras se encontravam naquele período em termos de inserção social em todos os aspectos. Esse documento reúne o pensamento de grande parte das mais proeminentes 
estudiosas, militantes e feministas e tem se tornado uma referência na área, como foi à versão da década anterior.

Conforme aponta este documento, nesse período o Brasil teve um crescimento econômico bastante significativo o que o colocou em destaque no cenário internacional. Mas até que ponto as mulheres tiveram seus direitos respeitados? Ou até que ponto as mulheres obtiveram avanços de proteção social? E as questões de discriminação, violência, igualdade no emprego em relação aos homens, como está? E o tempo despendido para os serviços domésticos e cuidados com os filhos, ainda é maior que aquele que os homens deveriam dedicar ao lar? Esses aspectos se tornam mais relevantes quando a partir do Censo Demográfico do IBGE de 2010, fica evidente que para uma população de 190.755.799 milhões de habitantes em que 93.406 .990 milhões são de homens e 97.348 .809 milhões são de mulheres o que projeta 3.941.819 milhões de mulheres a mais do que homens, ou seja, aproximadamente $2,07 \%$ do total da população. Nesse contexto, o emprego que antes excluía a mulher, hoje é considerado como fundamental no crescimento econômico e na composição do salário das famílias brasileiras. Conforme IBGE (2012), no período de 2000 a 2010 a autonomia das mulheres e a igualdade de gênero passaram a se constituir em condições essenciais para o combate à pobreza, à fome e às doenças, além de iniciativas com o intuito de se estimular o desenvolvimento verdadeiramente sustentável incluindo aí as mulheres.

As mulheres nesse período conseguiram, cada vez mais, se fazer presente no mercado de trabalho, com níveis de escolaridade maior do que dos homens. A questão da disparidade do nível de escolaridade entre homens e mulheres, com grande vantagem para elas, já era visível no Censo Demográfico IBGE de 2000 e ficou evidente no Censo Demográfico IBGE 2010. Tais aspectos trouxeram mudanças significativas no comportamento social feminino, no âmbito público, bem como no aspecto privado. Isso teve reflexos diretos na Pesquisa Nacional por Amostra de Domicílios de 2011, quando as mulheres passaram a ser citadas como pessoas de referência das famílias. Independentemente da situação de casal com ou sem filhos, cresceu consideravelmente a proporção de mulheres que se tornaram as responsáveis pelos núcleos familiares de 2001 a 2011. Nas situações de casais sem filhos a proporção foi de $4,5 \%$ para $18,3 \%$, e nos núcleos de casais com filhos a proporção foi de $3,4 \%$ para $18,4 \%$ nesse período. Nas situações monoparentais, as mulheres se mantiveram como a maioria, 89,6\% em 2001 e 88,7\% em 2011. Mesmo com as condições apontadas, a discriminação de gênero se faz presente na estrutura social brasileira. Como aponta o IPEA (2011):

[...] as mulheres têm consolidado, ao longo das últimas décadas sua participação no mercado de trabalho no Brasil, que deixa, aos poucos, de ser percebida como secundária ou intermitente. A inserção das mulheres nesta realidade é, no entanto, marcada por diferenças de gênero e raça. Além de estarem menos presentes do que os homens no mercado de trabalho ocupam espaços diferenciados, estando sobrerrepresentadas nos trabalhos precários. Ademais, a trajetória feminina rumo ao mercado de trabalho não significou a redivisão dos cuidados entre homens e mulheres, mesmo quando se trata de atividades remuneradas [...] (IPEA, 2011, p.27). 
A discriminação de gênero, homens versus mulheres, pode ser percebida a partir dos dados apontados pelo próprio IPEA (2011) com base no Censo Demográfico 2010. A segmentação ocupacional indica que as mulheres (especialmente as negras, e a partir daí uma dupla discriminação: gênero e raça) estão mais concentradas nos serviços sociais, ou $34 \%$ da força de trabalho feminina. Esse grupo envolve serviços de cuidado em sentido amplo como atividades de educação, saúde, serviços sociais e domésticos. Os homens, com maior representação negra, se encontram em maior número na indústria da construção civil. Em 2009 esse setor empregava 13\% dos homens e menos de $1 \%$ das mulheres.

O salário é outro indicador de discriminação desse tipo de gênero, pois de acordo com o Censo, o rendimento mensal dos homens com ocupação formal (carteira profissional assinada) foi de $\mathrm{R} \$ 1.392,00$ enquanto que as mulheres tiveram rendimento $30 \%$ abaixo do dos homens, $\mathrm{R} \$$ 983,00 , com maior concentração feminina no setor de serviços sociais.

Resquícios de uma sociedade leiga, regida por um processo industrial que tinha por objetivo apenas a produção, a qualquer custo. Esse cenário se consolidou como consequência de um início crescente da industrialização e da urbanização que mais tarde, após muita luta a favor dos direitos femininos, resultaria em novas perspectivas de trabalho e atuação para as mulheres (Del Priore \& Bassanezi, 2007). Dentro dessas novas perspectivas de inserção da mulher na sociedade, está a carreira militar.

\subsection{Relações de gênero e poder}

Mais um indicador que pode ser utilizado para medir à discriminação de gênero é o poder. Segundo o portal Mulheres do Brasil ${ }^{1}$, com base no último relatório (2009/2010) do Observatório Brasil da Igualdade de Gênero, cujo tema-foco foi "Mulheres, Poder e Decisão", as mulheres, apesar de representarem mais da metade da população e do eleitorado brasileiro e terem maior nível de escolaridade representando praticamente $50 \%$ da população economicamente ativa, não conseguem ocupar nem $20 \%$ das vagas dos cargos parlamentares, dos executivos federal, estadual ou municipal; dos cargos do primeiro escalão do executivo, do judiciário, dos sindicatos e até mesmo em reitorias das universidades públicas. A participação feminina nos cargos parlamentares e executivos a partir das últimas eleições gerais no Brasil reflete uma realidade mundial.

Segundo esse mesmo Portal, existem diferenças nas proporções de mulheres dirigentes, $4,4 \%$, para $5,9 \%$ dos homens dirigentes, diferença de 1,5 pontos percentuais que permanece desde o ano de 2003, segundo estudo que a Secretaria de Políticas para as Mulheres (SPM) elaborou. A maior disparidade da proporção entre mulheres e homens ocupando cargos de direção ocorre em estados das regiões Centro-Oeste, Sudeste e Sul. Nas demais regiões as proporções se aproximam mais. A baixa participação feminina nos espaços de poder está ligada ao limitado acesso das mulheres à esfera pública, à cultura da divisão sexual do trabalho, ao não compartilhamento de tarefas domésticas e familiares e ao preconceito relacionado à gênero, homens versus mulheres. No setor privado, também as diferenças de gênero seguem a tendência

\footnotetext{
${ }^{1}$ Mulheres do Brasil. In: PORTAL BRASIL. Brasília, DF, 2013. Disponível em: <http://www.brasil.gov.br/secoes/mulher/desigualdade-de-generos/mulheres-x-homens>. Acesso em: 18 jul. 2015.
} 
do setor público, de ocupação feminina de $20 \%$ a $30 \%$ dos cargos. Estudos da empresa Catho Online, realizados em 2009 com 89.075 mil empresas, indicaram que apenas 21,4\% dos cargos de chefia eram ocupados por mulheres, o mesmo ocorrendo em estruturas como sindicatos e cargos de livre nomeação e exoneração pelo Poder Executivo. Além disso, quanto mais alto o cargo, menor a participação das mulheres.

Por muito tempo existiu e, infelizmente ainda existe em algumas frentes, conforme cita Carreira et al., (2001), o paradigma de que poder é algo conferido apenas aos homens devido as suas características. Fato que pouco exprime veracidade, cabendo aí uma análise mais acurada quanto ao conceito de entrega, e competências individuais. Com base nisso, Cappelle \& Melo (2010) levam em consideração aspectos relacionados a poder e gênero, uma vez que esses dois fatores permitem mapear o modo como ocorrem às disputas existentes na sociedade capitalista.

Independente do gênero há que se levar em consideração aquilo que diz respeito às qualidades individuais de cada ser humano, suas competências, desempenho, porém na prática o cenário ainda é outro conforme aponta Borges (2008, p.17), tendo em vista que: “[...], as mulheres não são avaliadas pelas suas competências individuais, mas pelo fato de serem mulheres".

A partir do enfoque levantado pela autora, compreender a significância das relações de empoderamento está além de compreender a imagem criada por uma sociedade altamente preocupada com a produção e a exploração do trabalho. Nesse contexto, ainda, cabe considerar a relação que Acker (2006) faz entre desigualdade e relações de poder nas organizações, que particularmente afeta as mulheres assim como outros grupos minoritários:

Eu defino a desigualdade em organizações como as disparidades sistemáticas entre os participantes no poder e controle sobre as metas, recursos e resultados; decisões no local de trabalho, como forma de organizar o trabalho, oportunidades de promoção e de trabalho interessante, segurança no emprego e benefícios, recompensas monetárias de pagamento e outros; respeito e prazer no trabalho e relações de trabalho. Nas organizações, variam o grau em que essas disparidades estão presentes e o seu nível de gravidade. Igualdade raramente existe no controle sobre os objetivos e recursos, enquanto recompensas monetárias de pagamento e outros são geralmente desigual. Outras diferenças podem ser menos evidentes, ou um alto grau de igualdade pode existir em determinadas áreas, como a segurança do emprego e benefícios. Regimes de desigualdade são altamente diversos em outras formas, mas também tendem a ser fluidos e mutáveis. Estes regimes estão ligados a desigualdade na sociedade envolvendo: a sua política, história e cultura. Práticas e interpretações particulares são desenvolvidas em diferentes organizações e em suas subunidades (Acker, 2006, p.443). 
Conforme cita Oliveira (2012) a instituição policial enquanto visa à ordem mantida, por meio do poder procura fomentar a "hegemonia da masculinidade" que foi construída ao longo dos anos na sociedade como, espaço apenas masculino, devido às peculiaridades de coragem, força, que por engano foram atribuídas por conta de uma má concepção histórica, apenas aos homens, o que evidencia um princípio congênito equivocado. Assim, com base no que expõe Acker (2006) e Oliveira (2012), pode-se dizer que na organização militar a mulher não é dona do seu destino, ou seja, ela não define os objetivos e metas que tem que alcançar e pelos quais é medida em termos de resultados. No comando das organizações militares, de forma maciça, estão presentes os homens ocupando as mais altas patentes em postos que definem os rumos estratégicos dessas organizações.

Oliveira (2012) acredita que a transferência de empoderamento demanda impreterivelmente, ações e comportamento objetivando a efetiva participação da mulher no processo de mudanças sociais que levem à concretização de práticas verdadeiramente democráticas, onde os agentes sociais desempoderados passem a fazer parte da tomada de decisões e, consequentemente, a compartilhar responsabilidades.

\subsection{Profissão Policial Militar: um novo mercado de trabalho em potencial para as mulheres?}

No Brasil o ingresso de mulheres em instituições armadas do Estado ocorreu em 1954, com a inclusão das primeiras mulheres na Guarda Civil de São Paulo. Na década de 1970 essa organização foi extinta e seu efetivo foi incorporado a Polícia Militar de São Paulo (Soares et al., 2005). A segunda instituição policial militar a admitir mulheres no País foi a Polícia Militar do Paraná (PMPR) na década de 1970.

Mais precisamente, de acordo com Schactae (2006) as mulheres entraram na PMPR no final da década de 1970, no dia 20 de outubro de 1977 quando 42 mulheres foram incorporadas ao efetivo dessa instituição e iniciaram o processo de formação no Centro de Formação e Aperfeiçoamento de Praças (CFAP), na Academia do Guatupê na cidade de São José dos Pinhais Paraná. No mês de dezembro de 1977 era publicada uma Diretriz do Comando Geral da PMPR definindo o papel das mulheres policiais na Polícia Militar do Estado.

Schactae (2006) entende que esse tempo entre a entrada das primeiras mulheres no quadro militar e a publicação do documento definindo seu papel na instituição demonstra que a PMPR não tinha bem claro qual seria a função, ou qual seria o papel das mulheres policiais. Segundo a autora, no mês de novembro de 1978, mais 42 duas mulheres ingressaram na PMPR, participando do 10 Curso de Formação de Sargentos Feminino realizado pelo CFAP. A diretriz que definia o papel das mulheres na PMPR foi revogada em 27 de novembro de 1979, quando foi substituída por outro documento intitulado: Finalidade e Emprego da Organização da Policia Feminina.

Importante ressaltar que entre o final da década de 1970 e o final da década de 1990 ocorreu o ingresso de mulheres em todas as instituições militares brasileiras. Vinte e seis anos 
mais tarde, em 2006 a Força Aérea Brasileira (FAB) formou a primeira turma de mulheres-piloto de aviação, o que pode indicar certo preconceito com relação à presença de mulheres nessa força militar.

Cappelle \& Melo (2010) analisam a Polícia Militar como uma organização que visa não o lucro, mas uma instituição ou sujeito jurídico que busca a interação social, honra, coragem e ordem mantida. Uma instituição herdeira de uma concepção de ambiente criado apenas para o sexo masculino que teve seu espaço marcado pela construção de uma nova identidade através do ingresso das mulheres no quadro efetivo e para desempenhar as mesmas funções que os homens. A inserção de mulheres não permite classificá-la como uma organização que perdeu sua identidade institucional, mas sim como uma adequação alcançada, por meio de lutas visando a igualdade de direitos e ocupação de espaços promovidas pelas mulheres, principalmente a partir das décadas de 1950 e 1960.

O ingresso na Polícia militar se dá através de concurso público em que o número de vagas destinadas as mulheres é igual ao destinado aos homens, ou seja, 50\%, no estado do Paraná, em conformidade com a Lei estadual no 14.804/2005.

Após a aprovação no concurso público tanto homens quanto mulheres são submetidas ao Exame de Capacidade Física (ECAFI), as mulheres realizam um teste físico diferenciado em relação ao teste masculino em que havendo aprovação o (a) candidato (a) passa para a próxima etapa que compreende ao Exame de Sanidade Física (ESAFI), posterior a esse exame ambos os sexos são submetidos à Avaliação Psicológica e finalmente a Pesquisa Social e Documental. Todas as etapas são eliminatórias.

A entrada das mulheres na Polícia Militar (PM) está inserida no que aponta Kalil Mathias (2005) como uma mudança no universo social das mulheres, em razão das constantes transformações pelas quais passou o processo político em nosso país. Segundo Kalil Mathias (2005), o novo contexto econômico-social se direciona por duas vertentes distintas: por um lado possibilitou novas oportunidades para as chamadas minorias, mas ao mesmo tempo trouxe consigo resultados trágicos. Assim a mulher, pelas suas próprias características enquanto potencial transformador se tornou conforme considera Kalil Mathias (2005, p.2): “[...] o ator paradoxal deste novo mundo, [...], pois, se essa nova ordem apresenta maiores e melhores condições de empregabilidade e cidadania para a mulher, também gera maior pobreza e menor assistência por parte de Estados cada vez menos soberanos".

Nas forças armadas, mais diretamente, Silva (2006) analisaram as mulheres que desempenham atividades militares, em que relataram várias dificuldades, o que ainda evidencia um princípio de desigualdade nascido a partir do preconceito. A análise trouxe a premissa de que a mulher militar se reconhece melhor no ambiente de trabalho no instante em que ela consegue incorporar menos características femininas como fragilidade e delicadeza e adota uma postura mais masculina, representadas pela liderança e coragem. Os autores concluem que as percepções tanto no meio corporativo, como pela sociedade se constrói e reconstrói na medida em, que são impostas pelo cotidiano. 
Lima et al., (2010) por meio de uma avaliação das relações de gênero no trabalho da polícia militar, buscaram elencar as barreiras encontradas na tentativa de ampliar os direitos das mulheres e na democratização das relações sociais. A pesquisa considera que as mulheres necessitam ganhar maiores aptidões físicas, contudo, maior do que a lacuna de força é preciso que haja por parte dos homens uma compreensão da importância da mulher no dia-a-dia da corporação policial.

Contudo conforme avalia Luz \& Fuchina (2009), a incorporação da mulher no mercado de trabalho amplia a abertura de novos horizontes, de tal modo que a partir do trabalho feminino, estas ultrapassam limites impostos pela sociedade, no que se refere à figura masculina então considerada dominante.

Frente a isso Braga (2012) evidenciou que a participação das mulheres no trabalho operacional da PM, esta regido por práticas de determinação, inovação e, sobretudo práticas efetivas de interações sociais, assim como anuncia e denotam novas práticas de fazer policiamento, onde à "fragilidade" da mulher é substituída por um modelo de uso de atributos femininos, como coragem, flexibilidade e dinamismo.

Cappelle et al., (2001) analisam que a cultura organizacional é agente que permite que sejam eximidas as percepções equivocadas de desigualdade de gênero pelas características femininas que são vistas como limitação no desempenho. Clancy (2007) avalia que os padrões culturais são responsáveis pela maioria dos comportamentos gerados de diferenciação de gênero existente entre homens e mulheres. Nesse contexto Etzioni (1966 apud Clancy, 2007), considera que a organização é caracterizada com propósitos e objetivos comum e explícito, através da divisão de papéis e de trabalho, de uma hierarquia de autoridade e responsabilidade. A exclusão por gênero é agravada por outros aspectos da vida organizacional, dentre eles se destaca a expectativa de que a atividade profissional não está limitada aos funcionários.

\section{MATERIAIS E MÉTODOS}

Para melhor conduzir esse estudo, optou-se por uma pesquisa de natureza qualitativa, pelo fato de melhor entender as emoções presentes no comportamento do indivíduo. Marconi \& Lakatos (2010) consideram que a metodologia qualitativa visa analisar e interpretar aspectos mais profundos, de forma a descrever a complexidade do comportamento humano. Creswell (2010), Cooper \& Schindler, (2011) consideram que a pesquisa qualitativa busca interpretar, descrever, decodificar, traduzir, entender e expor o significado de certos fenômenos, condição que não se enquadraria em estudo de cunho quantitativo.

$\mathrm{Na}$ operacionalização da pesquisa, inicialmente foi entregue ao batalhão um ofício solicitando autorização para desenvolver a pesquisa juntamente com o plano de estudo e com o roteiro perguntas que seria aplicado. O roteiro de perguntas antes de ser aplicado passou por uma avaliação por parte do comando que se posicionou favorável, autorizando o estudo na unidade policial, porém foi solicitado que fosse reduzido o volume de questões. Após aprovação do estudo foram realizadas as entrevistas com as policiais conforme aceitação e disponibilidade por parte 
destas. As entrevistas com as policiais foram agendadas e ocorreram entre no próprio batalhão durante 30 a 40 minutos cada.

O estudo foi conduzido por entrevistas com roteiro semiestruturado com questões adaptadas do estudo de Cappelle (2006). Na visão de Hair (2005, p. 163) "[...] permite ao pesquisador sentir-se livre para exercitar percepções importantes no acompanhamento da resposta a uma pergunta". O entrevistador pode optar por fazer perguntas que não foram de fato incluídas no roteiro. Essa abordagem reflete no surgimento de informações esclarecedoras, colaborando assim com as descobertas.

As entrevistas ocorreram em dois momentos: inicialmente com as mulheres policiais, e no segundo momento com o comandante do batalhão. De um total de 33 mulheres que compõe o BPM-PR pesquisado, foram entrevistadas oito mulheres que atuavam como soldado e tenente, e dois homens que atuavam como sargento e comandante do batalhão. As entrevistadas, visando garantir o anonimato, estão identificadas pela sigla Pfem que indica policial feminina.

Também foram utilizados dados secundários, sendo estes divulgados publicamente no site da Policia Militar do Paraná e ainda alguns dados cedidos pelo Departamento de Jornalismo da Policia Militar.

\section{APRESENTAÇÃO E ANÁLISE DOS RESULTADOS}

\subsection{Trajetória do ingresso das mulheres na PM-PR}

A primeira turma de mulheres do BPM-PR, começou na cidade de Curitiba no ano de 1977, e se formou um ano depois. Elas ingressaram como soldado e saíram como sargento. As primeiras classificadas saíam como 20 sargentos e as outras como 3o sargento. Em 1981 se formaram as primeiras oficiais, inclusive, todas as pioneiras no ingresso na corporação PMPR já estão na reserva remunerada, ou seja, aposentadas (Dados obtidos junto ao Depto. de Jornalismo da PMPR).

De acordo com os dados do departamento de jornalismo, a Polícia Militar funciona em formato de pirâmide, na qual a base é formada por soldados e o topo por coronéis, assim sendo tem-se mais soldados e menos coronéis. O número atual de mulheres oficiais é de 88 para 1.093 praças mulheres; em todo Paraná apenas duas mulheres estão no mais alto escalão, ocupando a função de Tenente-Coronel, sendo que uma delas é responsável pelo comando do batalhão na cidade de Curitiba e a outra na cidade de Maringá. Mas de acordo com o departamento, tem também mulheres que comandam as Unidades Paraná Seguro (UPS), além de outras atividades que são exercidas. Há atualmente um total de 19,5 mil integrantes entre homens e mulheres nos quadros: policial e bombeiro militar. $O$ pequeno volume de mulheres praças e oficiais ressalta 0 que foi analisado pelo IPEA (2011), em que a inserção das mulheres no mercado de trabalho ainda está marcada por diferenças, principalmente no quadro militar.

\subsection{Perfil das policiais entrevistadas}


Ao total foram entrevistadas oito mulheres, todas elas naturais da cidade onde está localizado um dos principais Batalhões de Polícia Militar do Estado do Paraná. A Tabela 1, traz o perfil das entrevistadas. Em um total de 33 mulheres que fazem parte do BPM-PR em estudo, há apenas uma mulher que ocupa a patente de tenente, isso indica que ainda é pequena a participação das mulheres no poder de comando dentro da organização militar.

Tabela 1: Perfil das Entrevistadas

\begin{tabular}{|c|c|c|c|c|c|c|}
\hline $\begin{array}{l}\text { Identific. } \\
\text { Entrevista }\end{array}$ & Patente & $\begin{array}{l}\text { Tempo de } \\
\text { Serviço }\end{array}$ & Idade & Formação & Filhos & $\begin{array}{c}\text { Estado } \\
\text { Civil }\end{array}$ \\
\hline Pfem1 & Soldado & 1 ano & 33 anos & Graduada em Pedagogia & $\operatorname{Sim}$ & Solteira \\
\hline Pfem2 & Tenente & 17 anos & 36 anos & Graduada em Serviço Social & Não & Separada \\
\hline Pfem3 & Soldado & 7 anos & 29 anos & Cursando Ciências Biológicas & Não & Solteira \\
\hline Pfem4 & Soldado & $\begin{array}{c}1 \text { ano e } 5 \\
\text { meses }\end{array}$ & 25 anos & Graduada em Ed. Física & Não & Solteira \\
\hline Pfem5 & Soldado & 17 anos & 38 anos & $\begin{array}{c}\text { Graduada em Ciências } \\
\text { Biológicas e Pós graduada em } \\
\text { Ciências Modernas }\end{array}$ & Sim & Casada \\
\hline Pfem6 & Soldado & $\begin{array}{c}1 \text { ano e } 3 \\
\text { meses }\end{array}$ & 30 anos & Graduada em Pedagogia & Não & Casada \\
\hline Pfem7 & Soldado & 17 anos & 36 anos & Ensino Médio & Não & Casada \\
\hline Pfem8 & Soldado & 17 anos & 44 anos & Graduada em Gestão Publica & Sim & Separada \\
\hline
\end{tabular}

A média de idade das entrevistadas é de 34 anos. Pode ser observado que sete das oito entrevistadas possuem o ensino superior e isso para a carreira pública e militar é favorável pelo fato que elas buscam ascensão de carreira no cargo público, o que nem sempre é reflexo da questão de aumento salarial, mas representa a percepção de qualidade nos serviços prestados, tanto em atividades administrativas como também no trabalho externo.

Outro ponto que cabe destaque dentro do perfil das entrevistadas está relacionado com três características do estado civil: ser solteira e possuir filhos e; possuir filhos, ser casada e o tempo de carreira. Nota-se que é uma realidade e tendência da mulher moderna. Onde existe o desdobramento de inúmeras atribuições e, sobretudo a conciliação de todas as atividades condizentes a ocupação no trabalho e este árduo trabalho se estende as atribuições do lar, seja atuando como mães, esposas ou até mesmo mães de família provedoras do sustento.

Esse desdobramento feminino para cumprir com as obrigações do trabalho, em dupla jornada, faz parte da mulher em alguns contextos culturais da sociedade brasileira que desde que nasce lhe são carreadas inúmeras obrigações e compromissos, como pode ser observado no depoimento da Pfem5.

[...], têm também aspectos negativos, trabalhamos por escalas então nunca você pode combinar nada e quando você não tem filhos você pensa mais na carreira, quando você tem marido e filhos já fica mais difícil. Você 
quer estar com a família. Eu sempre tento almoçar com eles, mas é difícil, você não pode se programar, só quando estou de férias aí programo alguma coisa. Aqui varia muito porque trabalhamos por escala. Agora, por exemplo, que está tendo evento na cidade, muitas vezes fazemos escala extra (Pfem5).

Segundo o comunicado do Instituto de Pesquisa Econômica Aplicada, IPEA (2012) a mulher gasta, em média, 26,6 horas semanal em atividades domésticas, enquanto que o homem dispensa 10,5 horas. Isso demonstra que a mulher gasta 2,5 vezes mais do seu tempo do que o homem nesse tipo de atividades. Dentre as pessoas entrevistadas na pesquisa do IPEA, $90 \%$ das mulheres declararam que desempenhavam atividades domésticas no lar contra $50 \%$ dos homens. Apenas na Região Sul do Brasil que $61 \%$ dos homens entrevistados declararam desenvolver algum tipo dessas atividades. Portanto, em algumas profissões a dupla jornada feminina se torna ainda mais massacrante e acentua a desigualdade dos gêneros homem e mulher na sociedade.

A análise dos dados foi desenvolvida por meio da análise de conteúdo. Para Bardin (1994, p. 18) "a análise de conteúdo é uma técnica de investigação que tem por finalidade a descrição objetiva, sistemática e quantitativa do conteúdo manifesto da comunicação". Assim, análise de conteúdo consiste num conjunto de técnicas de análise das comunicações e é composta por três etapas: pré-análise; exploração do material; tratamento dos dados e interpretação (Bardin, 1977).

O conteúdo explorado nas entrevistas realizadas com as policiais seguiu uma estrutura qualitativa de interpretação, bem como descrição das emoções identificadas em suas narrativas e forneceu bases para o desenvolvimento da estrutura teórica acerca do tema.

\subsection{O Ingresso da mulher na carreira militar no BPM-PR}

O ingresso da mulher no quadro militar no Batalhão investigado deu-se tardiamente, sendo que a primeira turma de mulheres policiais foi formada apenas no ano de 1996, quando 39 mulheres da primeira turma de Policiais Militares do Batalhão da Polícia Militar passaram a atuar nas atividades do policiamento da região. Do número de mulheres que compuseram a primeira turma, apenas algumas delas, de acordo com dados obtidos com a corporação, permanecem atuando como policiais no batalhão ou foram transferidas, outras passaram em outros concursos e solicitaram baixa do batalhão. A essas mulheres foi atribuído bravura por serem guerreiras ao ponto de quebrar o paradigma de que a carreira militar era apenas para homens, isso é evidenciado nas palavras da Pfem7.

As mulheres até podiam fazer concurso para a PM, em Curitiba, por exemplo, mas ai tinha que se inscrever lá, fazer a prova lá, e trabalhar lá. Na cidade a primeira turma de mulheres foi em 1996, foi bem tardia a inclusão de mulheres no quadro militar. Hoje você faz concurso nível regional e pode escolher a cidade para onde quer ser destacada, e tem um 
percentual de vagas igual ao dos homens. Hoje estamos comemorando 159 anos da atuação da Policia Militar no Paraná e na polícia estamos a aproximadamente 17 anos de atuação das mulheres (Pfem7).

Em um contexto histórico marcado pela ideia de que a mulher é o sexo frágil, conforme refletido por Whitaker (1988 apud Oliveira, Gaio \& Bonacim, 2008, p. 93) “[...] quando uma menina manifesta ousadia ou agressividade, ela é geralmente barrada para que se possa produzir mais tarde a mulher profissional ideal, aquela que aceita as tarefas secundárias e sufoca seu talento nos bastidores da história". Um pouco dessa visão está presente nas palavras do comandante do destacamento e da Pfem1, nos trechos a seguir:

Antes a discriminação era maior, inclusive o quadro de promoções chegava até capitão, encerrando neste posto a carreira. Desde a década de 1990 os quadros foram unificados e concorrem em igualdade de condições até o posto de Coronel. Acredito que grande parte do preconceito já foi rompido, por isso elas estão em pé de igualdade com qualquer outro policial, não sendo constatado muitas nuances em relação ao gênero. (Palavras do comandante)

O processo de evolução e reconhecimento da mulher na sociedade foi longo. Pouco a pouco as mulheres buscam mudar um contexto histórico marcado pela construção de um mundo rodeado pelo estigma, onde apenas o homem poderia participar em todos os setores de trabalho. Isso pode ser mais bem compreendido nos trechos das entrevistas de Pfem1 e Pfem3.

É grande a evolução da mulher, hoje ela está ocupando cada vez mais espaço na sociedade em todos os ramos, eu, por exemplo, não tive estímulos, entrei para a polícia por vontade própria, eu queria isso pra mim. A mulher é capaz de conquistar mais espaço, mas ela tem que enfrentar os tabus que são impostos pela sociedade, nós mulheres muitas vezes somos muito mais guerreiras do que os homens (Pfem1).

A mulher está cada vez mais subindo de cargo e temos as mesmas capacidades e podemos chegar aos mesmos postos de trabalho, nas mesmas funções que antes apenas os homens executavam. Eu pretendo seguir carreira aqui, fazendo concursos internos para cabo, sargento $e$ tenente quem sabe. Eu me inspiro muito nas mulheres que fizeram carreira e história na polícia, admiro muito a tenente, ela entrou como soldado como eu, quando eu entrei ela era cabo e hoje é oficial é uma pessoa que com humildade, seriedade no trabalho, enfim luta pelo espaço que ela quer, sempre está tentando mudar sua história (Pfem3). 
Analisando as falas expressas pelas policiais, reconhece o quanto houve de evoluções das mulheres nesse ambiente organizacional. Elas possuem características singulares que expressam uma realidade de conquistas, e buscam incessantemente suprimir padrões impostos pela sociedade conservadora. Na visão de Estanque \& Costa (2012) é por essas e outras razões que o feminismo constitui um campo central nos atuais debates e um elemento decisivo para compreendermos os movimentos sociais, presentes e passados.

Em uma organização militar, que carrega diferenças expressas pelo então militarismo, onde homens e mulheres atuam em favor do combater a criminalidade, executando atividades inerentes a sua função, ainda pode ser considerado como um espaço limitado. Nesse ponto, por vezes se repele a ideia de que é um trabalho para homens. Porém quando se busca na história, logo se reflete que, para a mulher o único trabalho que então era conveniente exercer era àquele em que ela permanecesse onde os olhos do seu esposo alcançassem, ou seja, apenas nas atividades domésticas, conforme o que foi descrito por Del Priore \& Bassanezi (2007).

Nesse sentido o trabalho militar para a mulher, ainda que seja algo que aos poucos vai sendo ocupado por mulheres, representa a grandiosidade e a superação de limites impostos, por se tratar de um trabalho que ao mesmo tempo em que expõe tanto homens como mulheres, é representado pela intensidade com que cada um atua juntamente com sua equipe de trabalho, visando proporcionar uma sociedade pacificada onde prevaleça a justiça.

É uma profissão como qualquer outra, eu penso assim: independentemente de onde você trabalha você tem que se dedicar ao máximo pra fazer um trabalho bem feito, para atender as pessoas que precisam de atendimento. No início você passa por todas as atividades seja no administrativo como na rua, é assim que você adquire preparação para atuar onde te escalarem. Mas assim, se há o deslocamento de uma viatura para atender a uma ocorrência, tem pessoas por traz disso, tem o 190 que é onde trabalho, tem a logística, engloba todos de todas as funções, ou seja, todos são importantes aqui dentro. Nosso maior desafio aqui é combater a criminalidade, isso independe de ser homem ou mulher, é trazer tranquilidade para a cidade (Pfem6).

Pode ser observado de acordo com a descrição da Pfem6, que assim como em uma organização comum, a organização militar depende do trabalho em coletividade. Bourdieu (2009) avalia que a simbologia histórica não pode permitir que as mulheres sejam limitadas em suas funções ou na carreira a seguir, isso deixa margens conclusivas de que tanto homens como mulheres têm plenas condições de assumir cargos que antes foram apenas ocupados por homens.

\subsection{Mulher X Relações de Poder e empoderamento na PM}

Bourdieu, (2009) considera que para compreender de forma adequada a distribuição de poder e privilégios entre homens e mulheres e sua evolução no decurso do tempo, é preciso levar 
em conta que, por um lado as mulheres têm em comum o fato de estarem separadas por um coeficiente simbólico negativo e por outro lado a separação, uma das outras, pelas diferenças econômicas e culturais que afetam entre outras coisas, sua maneira objetiva e subjetiva de sentir e vivenciar a dominação masculina.

Há, no espaço militar, obediência conforme a graduação que as mulheres ocupam normalmente tanto em empresas em geral como também na carreira militar, existe liberdade para definir quando se tem um cargo de chefia, e, por conseguinte a obediência por parte dos subalternos quando há um tempo maior de "casa" isso pode ser evidenciado nos depoimentos a seguir.

Eu não sou graduada para exercer poder, delegar funções, mas as pessoas me respeitam pelos meus dezessete anos de serviço, então muitas vezes obedecem, tem o respeito por antiguidade (Pfem5).

O princípio ativo do exercício de poder demanda não unicamente, mas principalmente, conforme Foucalt (1995 apud Cappelle, 2006), do elemento liberdade, nessa colocação pressupõe que há poder onde existe liberdade, não existindo relações de poder onde as determinações são consideradas saturadas, como nos traços marcados pela escravidão, onde a coação predominava, enfim quando o indivíduo tem uma condição transferida a ele de liberdade a partir disso exerce poder sobre os demais. Essa a liberdade da função que exerce e implica na tomada de decisão, apoiada, baseada em algo que Ihe transfira embasamento:

Cada policial tem uma escala de 24 horas eu como tenente, executo atividades internas e quando é minha escala de ir para a rua eu vou, o policiamento é por minha conta, eu tenho que saber o que tem que ser feito, naquele momento eu represento o comando. Por exemplo, troca de tiros, eu verifico o que ocorreu, presto apoio, mas tem que saber o que fazer conforme o que aprendi na doutrina [tempo de escola militar] (Pfem2).

A liberdade consiste então, conforme Foucalt (1995 apud Cappelle, 2006), no livre arbítrio atribuído a determinadas pessoas, elas estando na condição de exercer poder sobre os demais mediante autorização e aprovação do superior, como parte executora de normas e regras. 0 trabalho militar é marcado pela regência de normas e regras que devem ser cumpridos a todo instante tanto por homens como por mulheres, não havendo, portanto, diferenciações, faces do militarismo em que as pessoas devem ter posturas diferenciadas de pessoas comuns da sociedade. Isso pode ser claramente observado nas palavras da Pfem1.

Depois que você entra para a PM, você tende a mudar seus hábitos de lazer, por exemplo, passa a ser mais uma pessoa mais reservada. Há 
lugares em que você não pode mais frequentar, porque você pode se expor. Ou se frequenta algum lugar onde há grandes aglomerações de pessoas, você não fica mais no meio do povo, mesmo à paisana você tende a ficar mais afastado, observando o que acontece. Outra coisa que eu diria é em relação ao receio de segurança da família, muitas vezes quando o policial vai atender uma ocorrência, ocorre que você não marca a fisionomia dos envolvidos, mas eles te marcam, então a gente fica preocupada em relação à segurança da família, porque eles estão indefesos. (Pfem1).

Em decorrência de fatores que expõem as pessoas à aceitação e práticas de hábitos que visem seu anonimato, muitas vezes a sua rotina deve ser ajustada fazendo com que haja a privação quanto aos aspectos da vida pessoal, de lazer, e a não aceitação do que é normatizado pode incutir em penas até mesmo o afastamento da corporação.

Bourdieu (2009) avalia que as mulheres são excluídas das coisas sérias, dos assuntos públicos. Nesse enfoque o autor critica o modelo em que as mulheres durante muito tempo foram confinadas ao universo doméstico e às atividades associadas à reprodução biológica e social e da descendência.

Nesse ponto, atribui-se à mulher da contemporaneidade características que fazem com que essas ocupem espaços diferenciados na sociedade, em relação às mulheres do início do século $X X$, por exemplo. Sobretudo, a sociedade ainda atribui maiores desafios e dificuldades que essas encontram pelo caminho que por vezes são maiores do que os homens, conforme expresso nas palavras da Pfem3 e da Pfem1.

Minha dificuldade foi conciliar o estudo com a carreira militar, eu fazia faculdade quando entrei e então tinha que estudar a ao mesmo tempo me adaptar a rotina militar, os treinamentos que a gente faz também são bem puxados, mas quando você está determinada a entrar para a PM, sabe que vai ser assim, mas eu supero tudo isso com muita dedicação (Pfem3).

Considero que a minha maior dificuldade e não apenas a minha, mas de todas as mulheres que ingressam na polícia, está em superar as dificuldades enfrentadas durante a formação das policiais, o preparo físico exigido é muito grande. Para os homens isso é diferente porque muitos adquirem força física e resistência quando se alistam no serviço militar obrigatório. No início você leva um tempo até se enquadrar e acostumar é necessário não apenas um bom preparo físico, eu diria também psicológico, porque não é fácil. Mas tudo isso é preciso porque é na rua que você depende de tudo isso, e as dificuldades são maiores (Pfem1). 
À mulher sempre foi colocado, nos ensinamentos dos pais que ela deveria ser dona de casa, cuidar dos afazeres domésticos e não ser a provedora do sustento de sua família. Graças às conquistas da mulher na sociedade capitalista, que prime pela produção e resultados econômicos, essas mulheres foram transferidas maiores responsabilidades. Hoje, muitas são provedoras do sustento dos seus lares, buscam uma história de vida onde exista o avanço da mulher. A mulher que pouco a pouco conquistou seu espaço na sociedade é aquela mesma que ontem era condicionada por um sistema machista assim como descrito por Probst \& Ramos (2003).

Muito mais atuantes, hoje as mulheres enfrentam desafios, superando-os com muito trabalho. Sem perder sua feminilidade avançam inspiradas, não apenas nas mulheres que fizeram história, mas criando a sua própria, lapidando-a cada dia mais na tentativa de demonstrar suas qualidades. O que foi descrito pela Pfem1 e pela Pfem3 tem uma coerência significativa com o que foi levantado por Silva (2006) e Cappelle \& Melo (2010) em relação as dificuldades encontradas e acima de tudo à adequação ao sistema militar normas, regras, doutrina e costumes que muitas vezes a própria policial tem que se ajustar a ele. Assim como em suas funções seja ela administrativa ou trabalho de policiamento externo haverão diferenças de postura no trato com as pessoas, na maneira de se impor diante as diversas situações, mas presando pelo comportamento militar que se vale da ordem social e justa.

Quando questionadas sobre a evolução da mulher no mercado de trabalho e, principalmente, na carreira militar houve uma considerável discordância no que tange a exclusão destas, como pode ser observado no depoimento a seguir.

A mulher para ser policial não precisa deixar de lado suas características femininas, pelo contrário tem certas situações que precisa ter muita força física, é claro, mas não que venha perder sua feminilidade. Eu não considero que liderança e coragem sejam características de homem apenas. A mulher tem muita coragem sim (Pfem3).

Sempre muda... Você fica mais tranquila por causa da estabilidade do serviço público. Muda no lado pessoal, você acaba se tornando... Eu diria menos sensível (risos), você vê as coisas com mais naturalidade (Pfem2).

Não vejo que a polícia militar seja um novo mercado de trabalho para as mulheres, porque de tudo a pessoa tem que se identificar com a atividade, não é porque tem estabilidade, ou porque é bem remunerado, mas as mulheres estão aptas para isso, não é só um campo de trabalho para homens (Pfem5).

No policiamento as mulheres e os homens têm que adotar uma postura que inspire confiança e ordem. A mulher atuante na polícia militar consegue transmitir seriedade, respeito, e 
em algumas ocasiões o instinto materno e protetor se sobressai como pode ser observado na fala da Pfem5.

Nas ocorrências depois que você tem filhos você sente o instinto materno, se sente mais responsável. Uma vez eu fui atender a uma ocorrência onde moravam o casal e vários filhos, uma casa simples, o pai bêbado, queria bater na mãe e eu perguntei à criança: onde vocês dormem? E a criança respondeu dormimos com o pai e a mãe, na mesma cama. Sabe! Eu como policial pensei que isso poderia ser portas [abertas] para abuso sexual, aos menores. Na hora que fomos sair uma das crianças segurou minha mão $e$ disse: tia, me leve com você, por favor, e isso comove a gente. Outro caso de aborto que eu atendi, a mãe abortou a criança, colocou dentro de um saco plástico e jogou, e eu como tenho duas meninas, queria tanto um menininho e ela não o quis. Mas de tudo isso tem histórias com final feliz também, tem uma história de uma policial do PROERD, [Programa Educacional de Resistência às Drogas e a Violência], que adotou quatro crianças órfãs, e de outra também que adotou hoje ela é da PRF [Polícia Rodoviária Federal]. A gente se sente na obrigação de ajudar (Pfem5).

Na dinâmica social, o instinto materno descrito é uma aptidão nata e intuitiva da mulher, de proteger, de cuidar, de preservar, sendo muito mais presente na policial feminina e acaba sendo mais forte em relação aos homens. A mulher dentro da corporação acaba atuando de forma solidária, e assim como descrito por Cappelle (2006), o papel de mãe muitas vezes desempenhado externamente à corporação, dá condições de fortalecer uma imagem atuante como assistente social, habilidade que esta adquire já na infância.

Em outras circunstâncias a mulher também consegue ser menos reativa e mais analítica diante da situação, ou seja, muitas vezes ela tem "jogo de cintura", para resolver a situação da melhor forma possível, sem uso da força física e sim da negociação, preservando o militarismo não expressado pelo uso efetivo das armas.

Embora, muitas vezes a estabilidade, benefícios do trabalho na repartição pública consiga atrair pessoas a ingressarem nas frentes militares, sejam homens ou mulheres é preciso que, tal como em uma organização comum, haja o comprometimento em relação àquilo que será desempenhado.

Em cidades de porte menor, o número de mulheres na polícia tende a ser menor em relação aos homens, o que justificaria a desproporção no efetivo. Contudo, em um universo de 19,5 mil policiais em todo Paraná o número de mulheres ainda pode ser considerado pequeno. Tal número pode ser visto não apenas como um preconceito por parte da organização militar, como também pode ser colocado como uma questão de educação onde os preceitos masculinos se sobressaem na subjetividade feminina, de que o trabalho militar é apenas para homens.

\section{CONSIDERAÇÕES FINAIS}


Um dos desafios das mulheres na sociedade moderna reside no combate contínuo pela luta de igualdade nos direitos, com intuito de cada vez mais minimizar injustiças sociais, seja salarial, de gênero, cor, raça ou qualquer outra, e que muitas vezes são sofridas no ambiente de trabalho, na família ou na sociedade em geral. Não se admite que na sociedade capitalista, que indica avanços em todas as frentes, ainda permaneça situações de discriminação, de diferenciação para o trabalho de homens e mulheres.

Pelas narrativas das policiais foi possível identificar diferentes perfis com um mesmo objetivo em comum: a tentativa de mudança de paradigmas criados pela sociedade. Não menores em força física, nem maiores em características que por vezes podem ser consideradas singulares, e típicas apenas das mulheres, como o instinto materno. Homens e mulheres, precisam estar integralmente inseridos na sociedade sem limitações, de acordo com características que Ihe são próprias, que devem ser respeitadas.

Portanto, em uma sociedade regida pela competitividade é preciso isolar qualquer tipo de preconceito e principalmente, no que se refere à mulher em determinadas funções, como por exemplo, no setor militar.

O status de policial incorpora um aspecto de poder o que por vezes é subtendido como uma postura que se assemelha a um estilo masculinizado, quando se analisa as mulheres na corporação. Por trás de uma farda haverá a manifestação de gênero, haverá um ser humano, haverá uma mulher, dotada de competências e que muitas vezes supera a competência de um homem.

Neste caso, a manifestação de poder é dotada das alianças formadas e sobrepostas dentro da corporação (entre homens e mulheres), visando o cumprimento diário de objetivos em comum, que é a ordem pública. Pelas narrativas das policiais foi possível identificar uma corporação que tenta quebrar tabus que muitas vezes, a sociedade assim como a própria mulher têm em relação a gênero, ao seu local de trabalho e as suas funções diárias desempenhadas.

No estudo realizado no batalhão percebeu-se na narrativa das policiais e principalmente na conversa com o comando que o policiamento tende a ser mais eficaz com o trabalho de homens e mulheres dentro da corporação, cada um ocupando e desempenhando suas funções da melhor maneira possível e não havendo desgastes com situações de conflito, também não sendo percebido situações de preconceito, de incertezas em relação à competência da mulher no ambiente de trabalho, por parte dos homens e nem por parte das próprias mulheres .

É reflexivo que muitas vezes a sociedade impõe preconceitos em relação a gênero. $O$ trabalho que a mulher militar desempenha é de uma nobreza singular. No entanto, ainda a quantidade de mulheres nas frentes militares, principalmente no batalhão estudado deixa margens de reflexão que ainda há certo preconceito em relação a função policial, mas que aos poucos caminha para uma mudança de valores e estes tendem a ser modificado a medida que a comunidade visualiza a importância da mulher nas mais diversas situações.

A contribuição do estudo consistiu em apresentar o trabalho da mulher na esfera militar. Alguns pontos podem ser considerados limitador para o estudo e isso diz respeito à disponibilidade de tempo de cada entrevistada, sendo necessário que as entrevistas fossem 
realizadas durante a realização de atividades das mesmas por falta de tempo devido a um evento que estava ocorrendo na cidade durante o período designado para as entrevistas.

Como sugestões para novos estudos cabe avaliar as percepções dos homens em relação ao papel desempenhado pelas mulheres sociedade atual e, ainda, avaliar os níveis de qualidade de vida desses profissionais, tendo em vista que no Paraná há poucos estudos que tem uma organização militar como objeto de estudo.

\section{REFERÊNCIAS}

Acker, J. (2006). Inequality regimes gender, class, and race in organizations. Gender \& society, 20(4), 441-464.

Barbosa, R. P. (2013). Relações de gênero e a lógica da competência no mercado de trabalho. Revista de Carreiras e Pessoas (ReCaPe). ISSN 2237-1427, 3(2).

Bardin, L. (1977). Análise de conteúdo. Lisboa, Portugal: Edições 70.

Bardin, L. (1994). Análise de conteúdo. Lisboa: Edições 70.

Borges, E. P. (2008). As agentes da Polícia de Segurança Pública e as limitações de progressão na carreira policial. Dissertação de Mestrado, Universidade Aberta, Lisboa, Portugal, $145 f$.

Bourdieu, P. (2009) A dominação Masculina. Tradução Maria Helena Kühner, 6.ed. Rio de Janeiro: Bertrand Brasil.

Braga, É. D. (2012). Mulheres policiais nas unidades operacionais da PMSE: surpresas e mobilidade em meio às práticas ostensivas. Dissertação de Mestrado em Sociologia, Universidade Federal de Sergipe, São Cristovão.

Calás, M. B., Smircich, L. (2007). Do ponto de vista da mulher: abordagens feministas em estudos organizacionais. In: CLEGG, S.R. et al. (Org.). Handbook de estudos organizacionais: modelos de análise e novas questões em estudos organizacionais. 1.ed. São Paulo: Atlas.

Camargos, M. C. S., Riani, J. L. R., Marinho, K. R. L. (2014). Mercado de trabalho e gênero: uma análise das desigualdades em Minas Gerais. Revista Pretexto, 15(2), pp.41-57.

Cappelle, M. C. A. (2006). O trabalho feminino no policiamento operacional: subjetividade, relações de poder e gênero na oitava região da polícia militar de Minas Gerais. Tese de Doutorado em Administração, Universidade Federal de Minas Gerais, Centro de Pós-graduação e Pesquisa em Administração- CEPEAD, $378 f$.

M. C. A., Cramer, L., Netto, A. de P. (2001). Relações de gênero na polícia: a construção das representações sociais do masculino e do feminino em uma organização militar. In: Encontro da Associação Nacional de Pós-graduação em Administração, ANPAD, Anais... Campinas.

M. C. A., Melo, M. C. O. L. (2010). Mulheres policiais, relações de poder e gênero na Policia Militar de Minas Gerais. Revista de Administração Mackenzie (RAM), 11(3) edição especial, São Paulo, pp.71-99.

Carreira, D., Ajamil, M., Moreira, T. (2001). Mudando o mundo: a liderança feminina no século 21. São Paulo: Cortez, 232p. 
Clancy, S. (2007). ¿Por qué no hay más mujeres em la cima de la escala corporativa: debido a estereótipos, a diferencias biológicas 0 a escogencias personales? Academia, Revista Latinoamericana de Administracion, 38, pp.1-8.

Cooper, D. R., Schindler, P. S. (2011). Métodos de Pesquisa em Administração. Tradução luri Duquia Abreu. Revisão Técnica Fátima Cristina Trindade Bacellar. 10. ed. Porto Alegre: Bookman.

Creswell, J. W. (2010). Projeto de Pesquisa: método qualitativo, quantitativo e misto. Tradução Magda Lopes 3. ed. Porto Alegre: Artmed.

Del Priore, M., Bassanezi, C. (orgs). (2007). História das mulheres no Brasil. 9. ed. São Paulo: Contexto.

Estanque, E. (2006). A questão social e a democracia no século XXI: participação cívica, desigualdades sociais e sindicalismo. Revista Finisterra, pp.77-99, Lisboa.

Estanque, E., Costa, H. A. (2012). Trabalho, precariedade e movimentos sociolaborais. In: CASACA, S. F (org.). Mudanças Laborais e Relações de Gênero: novos vetores de (des) igualdade. Lisboa/Coimbra: Almedina.

Fernandes, R. A. S., Lima, J. E., Santos, C. M. (2008). A exclusão social de mulheres jovens, com idade entre 15 a 24 anos, no mercado de trabalho no Brasil. Revista de Economia e Administração, 7, pp.125-136.

Gurgel, T. (2010). Feminismo e luta de classe: história, movimento e desafios teórico-políticos do feminismo na contemporaneidade. Anais do Seminário Internacional Fazendo Gênero 9: Diásporas, Diversidades, Deslocamentos - UFSC, Florianópolis, SC.

Hair Jr, J. F., Babin, B., Money, A. H., Samouel, P. (2005). Fundamentos de Métodos de Pesquisa em Administração. Tradução: Lene Belon Ribeiro, Porto Alegre: Bookman.

IBGE. Censo demográfico de 2010: características da população. Disponível em: <http://www.ibge.gov.br/home/estatistica/populacao/censo2010/caracteristicas_da_populacao/r esultados_do_universo.pdf>. Acesso em: 18 jul. 2016.

IBGE. Síntese de indicadores sociais: uma análise das condições de vida da população brasileira Estudos e pesquisas. Informação demográfica e socioeconômica 29. 2012. Disponível em:

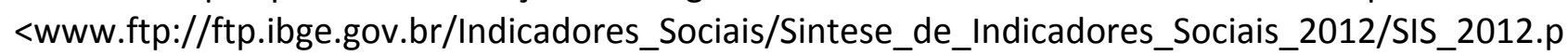
df>Acesso em: 18 jul. 2016.

IPEA. Retratos das desigualdades: gênero e raça. 4ạ ed. 2011. Disponível em: <http://www.ipea.gov.br/retrato/livreto.html>. Acesso em: 18 jun. 2016.

IPEA. Mulheres dedicam muito mais tempo ao trabalho doméstico. 2012. Disponível em: <http://www.ipea.gov.br/portal/index.php?option=com_content\&view=article\&id=14321>. Acesso em 12 ago. 2015.

Kalil Mathias, S. (2015). As mulheres chegam aos quartéis: gênero e forças armadas no cone sul. In: Anais do ANPUH - XXIII Simpósio Nacional de História, Londrina.

Lima, S. R., Castro, A. P. S., Cruz, M. H. S. (2010). Relações de gênero no trabalho: um estudo no $3^{\circ}$ batalhão da Policia Militar (Itabaiana/SE). Revista Fórum Identidades. Itabaiana: GEPIADDE, ano 4, 7. 
Luz, A. F., Fuchina, R. (2009). A evolução histórica dos direitos da mulher sob a ótica do direito do trabalho. In: Anais do Seminário Nacional de Ciências Políticas da UFRGS.

Marconi, M. A., Lakatos, E. M. (2010). Metodologia cientifica: ciência e conhecimento científico, métodos científicos, teoria, hipóteses e variáveis, metodologia jurídica. 5. ed. São Paulo: Atlas.

Oliveira, L. S. (2012). "Teto de vidro" relações de gênero, relações de poder e empoderamento das mulheres na Policia Militar. Tese de Doutorado, Programa de Pós-Graduação em Estudos Interdisciplinares sobre Mulheres, Gênero e Feminismo, 222f. Salvador.

Oliveira, A. R., Gaio, L. E., Bonacim, C. A. G. (2009). Relações de Gênero e ascensão feminina no ambiente organizacional: um ensaio teórico. Rev. Adm. UFMS, Santa Maria, 2(1), pp.80-87.

Probst, E. R., Ramos, P. (2003). A evolução da mulher no mercado de trabalho. Instituto Catarinense de Pós-Graduação, p.1-8.

Schactae, A. M. (2006). A representação do feminino na legislação da PMPR. Anais do VII Seminário Internacional Fazendo Gênero: gênero e preconceitos, UFSC/UESC.

Silva, L. D. S. (2009). Quadro feminino de oficiais (QFO): a pedagogia militar. Programa de Pósgraduação em Ciências Aeroespaciais. In: Anais do II Seminário de Estudos: Poder Aeroespacial e Estudos Estratégicos, UNIFA.

Silva, C. R. (2006). Mulheres em armas: um estudo etnográfico do segmento feminino das forças armadas brasileiras. Monografia de Graduação em Ciências Sociais, Universidade Federal de São Carlos. São Carlos.

Soares, B. M., Musumeci, L. (2005). Mulheres Polícias: presença feminina na Polícia Militar do Rio de Janeiro. Rio de Janeiro: Civilização Brasileira, pp. 15. 